\title{
Institutional and Individual Sentiment: Smart Money and Noise Trader Risk
}

\author{
Maik Schmeling ${ }^{\dagger}$ \\ Discussion Paper No. 337 \\ May 2006 \\ ISSN 0949-9962
}

\begin{abstract}
:
Using a new data set on investor sentiment we show that institutional and individual sentiment proxy for smart money and noise trader risk, respectively. First, using bias-adjusted long-horizon regressions, we document that institutional sentiment forecasts stock market returns at intermediate horizons correctly, whereas individuals consistently get the direction wrong. Second, VEC models show that institutional sentiment forecasts mean-reversion whereas individuals forecast trend continuation. Finally, institutional investors take into account expected individual sentiment when forming their expectations in a way that higher (lower) expected sentiment of individuals lowers (increases) institutional return forecasts. Individuals neglect the information contained in institutional sentiment.
\end{abstract}

JEL-Classification: G11, G12, G14

Keywords: investor sentiment, predictive regressions, noise trader, smart money

We would like to thank two anonymous referees and Lukas Menkhoff for very useful comments and especially Manfred Hübner for kindly providing the data.

${ }^{\dagger}$ Maik Schmeling, Department of Economics, University of Hannover, Königsworther Platz 1, D-30167 Hannover, Germany, schmeling@gif.uni-hannover.de 


\section{Introduction}

This paper empirically investigates two questions that have been subject to a large amount of research effort and debate in financial economics, namely (i) does investor sentiment matter for stock returns, and (ii) what is the difference between individual and institutional investors in financial markets?

While it seems to be generally accepted that institutions differ from indviduals due to their size and sophistication (Kaniel, Saar and Titman, 2005) there is considerable disagreement in which way these two investor groups differ and how this difference affects market processes like price formation and liquidity provision. Several studies find institutions to be informed investors or "smart money"1](e.g. Chakravarty, 2001, Jones and Lipson, 2004, Sias, Starks and Titman, 2004) and individual investors to be irrational noise traders or "dumb money" (Frazzini and Lamont, 2005, Bange, 2000). However, this evidence is accompanied by the finding that institutions deliberately herd in and out of stocks (see e.g. Nofsinger and Sias, 1999, Sias, 2004) and that they heavily rely on momentum-style strategies (Badrinath and Wahal, 2002, Griffin, Harris and Topaloglu, 2003, Temin and Voth, 2004). Furthermore, "dumb" individuals seem to earn excess returns by providing immediacy for institutional trading demands at high frequencies (Kaniel, Saar and Titman, 2005, Campbell, Ramadorai and Voulteenaho, 2005). Therefore, the evidence from real-world trading data so far is not conclusive regarding the role of these two investor groups.

The question whether sentiment, or the mood and expectations of investors, matter for stock returns is more controversial and supporters from the behavioral side (e.g. Shiller, 2003) and critics from the rational camp (e.g. Fama, 1998) have arguments in favour of this view or against it. While theoretical models have early incorporated

\footnotetext{
${ }^{1}$ We refer to institutions as smart money in the sense of informed investors (e.g. Campbell and Kyle, 1983) and not in the narrower context of mutual fund flows only as in Zheng (1999).
} 
the existence of noise traders into equilibrium asset pricing (Kyle, 1985, DeLong et al., 1990), empirical evidence on the relevance of investor sentiment does not provide clear findings (see e.g. the polar results in Brown and Cliff, 2005 and Wang, Keswani and Taylor, 2006).

We tie up these two questions and investigate whether sentiment of institutionals and individuals matters for aggregate stock market movements and whether the influence of sentiment of these two groups is systematically different. Using a new data set that covers both institutional and individual investors we find, first, that sentiment matters for several stock markets around the world and over intermediate horizons of up to one year. Second, there is a sharp difference between the two investor groups. Institutional investor sentiment forecasts stock returns correctly on average. Individual sentiment negatively predicts market movements in a way that is consistent with the hypothesis that overoptimistic (-pessimistic) noise traders drive markets away from intrinsic values. Third, in line with these findings, institutional investors become more pessimistic (optimistic) when they expect individuals to become more optimistic (pessimistic).

Therefore, our contribution to the literature is twofold. We first employ a new data set that covers genuine investor sentiment from a weekly survey, twice-separated on individual and institutional investors as well as on short and medium forecasting horizons based upon several major stock markets around the world. This data set allows us to analyze investor sentiment while controlling for factors like the geographical distance of a market relative to the home country, forecast horizon and sophistication of investors. This is new to the literature since previous studies have to rely on proxies for (mostly institutional) sentiment (e.g. Neal and Wheatley, 1998, Bodurtha, Kim and Lee, 1995, or Wang, Keswani and Taylor, 2006) or rather examine sentiment of individual investors for the US market exclusively (Kumar and Lee, 2004 or Lee, Jiang and Indro, 2002). 
Second, we contribute to the literature by directly extending a new empirical modelling approach from Brown and Cliff (2005) to the case of two investor groups. Earlier studies employing sentiment data have focussed on short run predictability in first or second moments (Lee, Jiang and Indro, 2002, Wang, Keswani and Taylor, 2006). Following Brown and Cliff (2005) we investigate longer term effects of sentiment on stock markets since the building up of excessive optimism or pessimism, i.e. sentiment, is likely to be a persistent process whose effects on stock prices would be hard to detect over short horizons. Whereas Brown and Cliff limit their analysis to individuals, we jointly analyse the impact of both individuals and institutions on stock prices and complement their approach with further analyses that all point to the main result of this paper: individual sentiment is a proxy for noise trader risk and institutions seem to be smart money.

The rest of the paper unfolds as follows: the next section derives testable hypotheses from earlier studies and section 3 describes the data set. Section 4, 5 and 6 show empirical results and section 7 concludes.

\section{Hypotheses and earlier literature}

One of the basic issues related to studies of investor sentiment deals with the question whether sentiment contains unique information for asset pricing. Indeed, there is lots of evidence that investor sentiment, moods or the awareness of investors for certain topics affect conditional moments of equity returns. This includes among others the high-volume premium documented by Gervais and Kaniel (2001), index additions and deletions (see e.g. Chen, Noronha and Singal, 2004) or rumors and talks in internet chatboards investigated by Antweiler and Frank (2003).

On a theoretical level, the model of Barberis, Shleifer and Vishny (1998) gives room 
for systematic under- and overreaction of stock returns due to shifts in investor sentiment. Using several proxies for investor sentiment Neal and Wheatley (1998) and Baker and Wurgler (2006) find that sentiment proxies heavily affect the cross-section of stock returns, e.g. that they affect the size effect or the relative prospects of different groups of stocks sorted by characteristics like volatility and dividend payments. These results seem to carry forward to the realm of real economic activity. Polk and Sapienza (2004) even find sentiment to have effects on the real economy by influencing managers' decisions to issue new shares when sentiment is high. Ang, Bekaert and Wei (2006) find survey measures of investor expectations to beat all traditional forecasting methods when predicting inflation in the U.S. which highlights the information contained in investor surveys. Therefore we expect that sentiment, as measured by genuine investor surveys, matters for stock returns for a period of intermediate to long horizons as in Brown and Cliff (2005).

Since financial economists typically view individuals and institutions differently due to their relative size and sophistication and many researchers find that both groups often take opposite positions when trading (e.g. Kaniel, Saar and Titman, 2005, Griffin, Harris and Topaloglu, 2005) we expect sentiment of individuals to have a different effect than sentiment of institutions.

Regarding the nature of the difference between individuals and institutions, we observe that Brown and Cliff (2005) find strong evidence for the hypothesis of excessive overoptimism which holds that noise traders who get overly optimistic (pessimistic) about a series of good (bad) news tend to push asset prices above (below) intrinsic values (see also Barberis, Shleifer and Vishny, 1998). Since many researchers view individuals as the proverbial noise traders (Kaniel, Saar and Titman, 2005) it implies that individual sentiment forecasts returns negatively, i.e. higher individual sentiment implies lower expected returns since asset price eventually come back to their fair values. Therefore our first hypothesis is, that individual investors' sentiment 
negatively predicts returns at longer horizons. As a by-product of this hypothesis, we also expect sentiment to have a contemporaneously positive effect on returns, i.e. higher individual sentiment pushes prices up.

Evidence from trading data implies that institutions are informed investors (e.g. Chakravarty, 2001) although, as noted in the introduction, there is also evidence on non-sophisticated behavior of institutions like herding. However, for the functioning of financial markets there must be at least some market participants who collect and interpret fundamental information to calculate fair asset prices. Moreover, recent research indicates that the influence of fundamental risk factors on returns is state dependent and therefore needs to be interpreted by investors (see inter alia Bacchetta and van Wincoop, 2004, Boyd, Hu and Jagannathan, 2005 or Conrad, Cornell and Landsman, 2002). Since this is a demanding task, we would expect institutions due to their size and sophistication to fulfill this function. Therefore, we expect institutional sentiment to be positively correlated with expected stock returns, i.e. institutional sentiment correctly predicts market returns over longer horizons. This makes up our second hypothesis.

Finally, given that there is noise trader risk in financial markets, DeLong et al (1990) show that equilibrium asset prices reflect a corresponding risk premium. We are obviously not able to test this directly, but expect that institutional investors take into account this noise trader risk. Therefore, we test whether institutions who expect higher optimism (pessimism) by individuals get more pessimistic (optimistic) since they heed that noise traders drive price above (below) intrinsic values. Our third hypothesis therefore is, that institutional traders take into account sentiment of individual investors when forming their expectations. 


\section{Data and descriptive statistics}

We use data based on a weekly survey, called sentix (sentiment index). These are collected by "sentix - behavioral indices" and are available on the internet via www.sentix.de to frequent participants of the survey. They are also obtainable inter alia via Bloomberg, Thomson Financial, Ecowin or Reuters. The survey distinguishes between answers from institutional and individual investors. Although everybody who wishes to join-in the survey is allowed to, once registered online, there is an identity check in the case of institutional investors: Only investors who register with an e-mail adress of an institutional investment firm (e.g. banks, brokers, asset managers) are allowed to vote for the category "institutional investor". Survey participation is not compulsory but frequent participation allows users to both access the time series of sentiment indices as well as special analyses by the operators of the survey - hence this provides an incentive to participate on a regular basis.

Participants are being asked anonymously what they think will be the direction of the market for the short (one month) and medium (six months) run for several major stock markets in Europe, the USA and Japan. They can choose three answers, namely "up", "unchanged" and "down" for both time horizons separately. We centre our investigation upon the medium horizon answer $2^{2}$ of both private and institutional investors for the DAX30 (DAX), EuroStoxx50 (ESX), Nikkei225 (NK), S\&P 500 (SP) and NASDAQ $100(\mathrm{ND}) \mathrm{U}^{3}$

The sentix survey covers the period from February 23, 2001 to February 11, 2005 and consists of 199 observations, as some weeks were not evaluated due to offical

\footnotetext{
${ }^{2}$ As we find short run sentiment to be very noisy which confirms the results in Brown and Cliff (2005) or Wang, Keswani and Taylor (2006).

${ }^{3}$ There is data on one more market, the German TecDAX, which is similar to the NASDAQ indices. However, this index experienced a major reconstruction in the middle of the sample, consequently we do not use the data on this market.
} 
holidays taken place during this time. The number of responses in the survey totalled to 52 immediately after the start of the survey in February 2001 and 561 in February 2005. The average response is 281 participants with a standard deviation of about 125. The average share of institutional responses is about $25 \%$. Furthermore, the differentiation into several major stock markets and different forecasting horizons is especially attractive. A disadvantage is the relatively small number of respondents at the beginning of the survey in 2001. At this time, it would have been possible to manipulate the index. However, this becomes more and more unrealistic towards the end of the sample with more than 500 survey respondents each week.

In order to make our data operational we first need a sensible measure to aggregate the survey answers. A common way to do this is to use the so-called bull-bearspread (Brown and Cliff, 2004) which is computed by the number of positive minus negative answers divided by the total number of survey participants. We thus define our bull-bear-spread $S_{t}^{i}$ for each of the five stock indices as

$$
S_{t}^{i, m}=\frac{\# P O S_{t}^{i, m}-\# N E G_{t}^{i, m}}{\# O B S_{t}^{i, m}}
$$

where $i$ denotes institutional $(i=I)$ or individual (or private, $(i=P))$ investors. The superscipt $m$ indicates the respective stock maket, i.e. $m=$ DAX, ESX, ND, SP or NK. \#POS $\left(\# N E G_{t}\right)$ being simply the number of positive (negative) voters in week $t$. Finally, $\# O B S_{t}$ denotes the total number of survey participants in week $t$ which is made up by positive, negative and neutral voters.

As a basic ingredient for the following analysis we also use log returns for each respective stock index. Descriptive statistics of these variables used can be found in Table 1. As one can see from Panel A of the table, stock returns display a typical behavior: they are not autocorrelated but show signs of heteroscedasticity. Panels B and $\mathrm{C}$ deal with institutional and private investors' sentiment. In short, the mean and median of each series is positive and the maxima and minima are far from 
their natural bounds minus one and plus one. Thus, there are no really extreme aggregate expectations in the sample. Furthermore, all sentiment series are highly persistent as can be seen from the low test statistics of the Ljung-Box (1987) test who clearly reject the null of no autocorrelation. This persistent behavior of the series will be taken special care of in the following analysis. Interestingly, adjusted for autocorrelation, most sentiment series seem to be well described by a normal distribution as indicated by the Jarque-Bera test in the last two rows of each panel.

Figure 1 plots the evolution of the stock maket index (right axis and bold dark line), individual (left axis and thin dark line) and institutional sentiment (left axis and thin grey line) for all five markets over the whole sample. As one can see, the two sentiment indices sometimes covary positively and sometimes negatively with no clear trend. Only for the NIKKEI 225 there seems to be a clear positive correlation between individual and institutional sentiment. Indeed, for the four European and US American markets, the correlation coefficients of individual and institutional sentiment are essentially zero whereas there is a correlation of 0.77 for the Japanese market. This is first evidence that, except for the NIKKEI, institutional and individual opinions about future market movements differ.

Finally, one might be concerned that the sentiment indices presented in Figure 1 are not only very persistent as indicated by the Ljung Box tests presented above but may even be unit-root nonstationary. Theoretically, there is a strong prior that the sentiment indices are stationary in the long run, because they are bounded between plus and minus one by construction. However, the series may well be nonstationary in a finite sample like ours. This poses a problem, because as is well known, the question whether a time series has a unit root or is just very persistent is unanswerable in finite samples (see e.g. the discussion in Hamilton, 1994, p. 444-447 or Cochrane, 1991). We present several unit-root tests for all ten sentiment indices in Table 2. On the $5 \%$ level, the null of a unit root is always rejected by the Phillips-Perron 
(1998) test, is almost always rejected by the Augmented Dickey-Fuller (1979) test (except for individual NIKKEI 225 sentiment) and is rejected for only 6 of the time series when using the more recent DF-GLS test of Elliot, Rothenberg and Stock (1996). Therefore, the tests offer no clear advise. Since we are mainly interested in the information contained in the levels of sentiment $t^{4}$, we will present analyses that explicitly take into account the high persistence in the sentiment indices and also analyses based upon the assumption that the time series are nonstationary. Finally, we investigate an implication of the so obtained results on the first differences of sentiment indices. Encouragingly, all three analyses are confirmative to each other.

\section{Long-horizon return regressions}

This section performs a simple and intuitive test for the existence of noise trader risk and smart money effects and establishes the main result of the paper. Extending the empirical framework of Brown and Cliff (2005) to the case of two investor groups we run predictive regressions of stock returns on past sentiment of both individuals and institutions. The results show that individuals consistently forecast the wrong direction whereas institutional sentiment forecasts returns correctly.

\subsection{Econometric methodology}

We closely follow Brown and Cliff (2005) in the empirical setup to ensure comparability of our results. However, contrary to them we include both institutional and individual sentiment in our analysis to jointly test for the existence of noise trader

\footnotetext{
${ }^{4}$ It is intuitive that e.g. a positive change in sentiment may have quite different effects on stock returns depending on whether the change occurs on a yet extremely bullish level or on a neutral level near zero.
} 
risk and smart money. Towards this end we estimate long-horizon return regressions of the form

$$
\frac{1}{k} \sum_{\kappa=1}^{k} r_{t+\kappa}^{e, m}=\beta_{0}^{(k), m}+\beta_{1}^{(k), m} S_{t}^{I, m}+\beta_{2}^{(k)} S_{t}^{P, m}+\Theta_{t}^{m} \gamma^{(k), m}+\varepsilon_{t}^{(k), m}
$$

with the average $k$-period excess return $5^{5}$ for market $m$ as endogenous variable and several predictors on the RHS. These predictors include sentiment of individual $S^{P, m}$ and institutional investors $S^{I, m}$ as well as typical macro and micro factors used in the asset pricing literature. These additional risk factors are collected in the matrix $\Theta$ and are detailed below. We employ known up-to-week $t$ information to forecast cumulative excess returns beginning in week $t+1$ only.

Equation (2) can be used to test hypotheses 1 and 2 discussed in section 2. If sentiment matters for stock returns the coefficients $\beta_{1}, \beta_{2}$ should be nonzero. For the existence of noise trader risk and overoptimism among individuals (hypothesis 1) we expect $\beta_{2}^{(k)}<0$ since overoptimism which pushes prices above intrinsic values eventually has to be reversed which implies that higher individual sentiment leads to low expected returns. For institutions to form correct expectations (hypothesis 2) $\beta_{1}^{(k)}>0$ must hold, i.e. higher institutional sentiment is followed by higher returns. Since the regression approach measures net effects of each regressor (net of all other regressors) it is possible to determine if institutional sentiment correctly predicts market movements net of fundamental $(\Theta)$ risk factors and noise trader risk $\left(S^{P}\right)$.

A common and nowadays well known problem with long-horizon regressions of the form above is, that they cannot simply be run by standard econometric tools even if robust covariance matrices are used. Several authors (see Stambaugh, 1999, Valkanov, 2003, or Ferson, Sarkissian and Simin, 2003) have documented this problem,

\footnotetext{
${ }^{5}$ Although investors are asked about their sentiment concerning simple returns we use excess returns to ensure comparability with the asset pricing literature. However, the results are almost the same when using log returns instead.
} 
which is mainly caused by highly persistent regressors that evolve as stochastic processes themselves. In this case OLS estimation results are at best consistent but no longer unbiased although all regressors are predetermined. For simple regressions with only one predictor it can be shown analytically that the bias in coefficient point estimates increases, the stronger the persistence of the regressors gets (Stambaugh, 1999). As we show in Table 1 our sentiment indices are highly persistent ${ }^{6}$ A further complication arises from the overlapping of the sums of returns, which induces a moving average structure to the error terms $\varepsilon_{t}^{(k)}$.

Different ways have been proposed to circumvent these problems, mostly relying on some form of simulation procedure (see e.g. the application in Brown and Cliff, 2005) or auxiliary regressions (Amihud and Hurvich, 2004). In order to establish comparability with the results of Brown and Cliff (2005) we follow them by simulating small sample confidence intervals and test statistics for the coefficient estimates of each return regression separately to overcome this spurious regression problem (Ferson et al, 2003). The procedure used is described in Appendix A1. There we also describe the ingredients to the matrix of control factors $\Theta$ which is slightly different across markets due to data availability for the respective countries.

\subsection{Estimation results and interpretation}

Results of this estimation-simulation procedure are depicted in Figure 2. The figure shows the estimated effect of a one standard deviation movement in institutional (left column of the figure) and individual (right column) sentiment for each horizon $k=1, \ldots, 60$ weeks and simulated small sample $95 \%$ confidence intervals.

The results are clear-cut and confirm our hypotheses 1 and 2. Institutional investors' sentiment correctly predicts long-horizon index excess returns for most horizons in

\footnotetext{
${ }^{6}$ Brown and Cliff (2005) also find individual sentiment in the U.S. to have high serial correlation.
} 
all five stock markets. Thus institutional investors are found to forecast future stock returns correctly if noise trader and fundamental risk is held fixed. This does not necessarily mean that their forecasts are always correct. It rather verifies that, on average and net of unpredictable factors, institutional sentiment gets the direction of future stock market movements right. This fits well for the assumption of institutions as rational arbitrageurs who collect and aggregate fundamental information since their sentiment contains information beyond that of several fundamental risk factors alone (which we include via $\Theta$ ).

On the contrary, rising individual sentiment has a negative effect on future stock returns and vice versa. This stands in line with the hypothesis that excessive optimism (pessimism) of noise traders drives prices above (below) fundamental values. This causes a subsequent reversal to intrinsic values so that individual sentiment and expected returns are indeed negatively related. Thereby we confirm the findings of Brown and Cliff (2005) for markets outside the U.S.

Since our investors are asked about their expectations regarding a six months horizon we also present estimation results of the two relevant parameters $\beta_{1}$ and $\beta_{2}$ for this horizon, i.e. $k=24$ in Table 3 . Reported are bias adjusted coefficients and p-values based upon simulated critical values for the t-test. We also report the percentage bias in coefficient estimates, denoted $\psi^{i, m}[7$, the simulated upper and lower critical values for the $t$-test on the $5 \%$ significance level, denoted $t^{u}$ and $t^{l}$, and an analysis of the forecast root mean squared error (RSME) and Theil's U. It can be inferred, that on this special forecasting horizon, some coefficients are significant only on the $10 \%$ level. The most impressive results stand for the two US American markets which have the highest $R^{2} \mathrm{~s}$, the highest covariance proportion of the root mean squared errors (RMSE) and the lowest p-values. The results for the two European and the Japanese markets are worse and not all of them are significant on the $5 \%$ level.

\footnotetext{
${ }^{7}$ Remember that $i$ indexes institutional $(I)$ and individual $(P)$ investors respectively.
} 
However, it is unlikely that investors report exact "24 week" sentiment but rather their general medium term expectations. These might be based upon a somewhat longer or shorter period which would explain the strong results for other periods as presented above. Finally, the simulated critical values for the t-statistics are much larger in absolute value than those employed in standard coefficient tests, which clarifies the need to adjust for the effects of persistent regressors.

The results shown in Figure 2 are also significant in economic terms and higher in absolute magnitude than those in Brown and Cliff (2005). There they find that a one standard deviation shock in sentiment leads to a cumulative decrease in excess returns of $7 \%$ over three years. We cannot examine this long horizons but our analysis shows that net effects of individuals over horizons of one year are approximately $-10 \%$ whereas institutional sentiment has an effect of roughly $+10 \%$ across markets. However, these results should not be interpreted easily as being evidence against the efficient markets hypothesis. First, the implementation of a trading strategy to exploit these relations has to take into account severe transaction costs since the underlying sentiment data arrives weekly. Second, there is large parameter uncertainty for the European market over horizons up to 36 weeks for institutional and up to 40 weeks for individual investors impact on returns. A longer horizon could well be outside the usual investment horizon of many investors. Third, our results reveal that institutional sentiment is likely to represent fundamental risk whereas individual sentiment is a proxy for noise trader risk. Therefore, positive excess returns from a trading strategy based on sentiment should turn out to carry significant risk from both sources. Fourth, out of sample data is needed to perform realistic tests for the profitability of such a trading strategy.

The analysis in this section directly accounted for problems of persistent regressors and their distorting effects on coefficient estimates and test statistics. However, if there really are unit-roots in our sentiment indices the analysis could be extended 
to directly deal with this problem in a more standard setup. We therefore present analyses based on VEC models in the next section which lead to confirmative results and yield some further insights into the dynamic relations of stock returns and investor sentiment.

\section{$5 \quad$ VECM analyses}

Nonstationarity is a common feature of many financial time series but correctly detecting unit roots in finite samples is notoriously difficult as discussed in section 3. Although there is a strong theoretical prior that the sentiment indices must be stationary in the long run it is not clear whether this is also true in our less than infinite sample. We therefore proceed with an analyses that treats sentiment indices as unit-root nonstationary.

The results obtained confirm the findings of the previous section and also show that individual sentiment has a contemporaneously positive relation with stock market returns as hypothesized in section 2 . Therefore, it is in line with the idea that noise traders push prices above intrinsic values. Insitutional sentiment has a contemporaneously negative relation with stock returns which is consistent with at least two recent findings in the literature: First, Evans and Lyons (2002) find evidence that private information in financial markets may forecast discount factors rather than cash-flows. This implies that a shift toward higher expected returns of institutions is accompanied by lower contemporaneous returns due to an increase in risk.

Turning back to the technical issues, if our sentiment indices are in fact $I(1)$, the most interesting case in economic terms would be the existence of a cointegrating relationship (Engle and Granger, 1987). Since we are dealing with three time series per market, individual sentiment, institutional sentiment and (log) levels of the stock 
market indices, we employ Johansen's (1991) trace test to test for the existence and number of cointegrating relations simultaneously. The tests assume no linear or quadratic deterministic trend but a constant in the cointegrating relation. The lag length is determined by the Schwartz Information criterion (SC) and uniformly chooses a lag length of one for all four European and US American markets and a lag length of two for the NIKKEI 225. Results for the trace tests can be found in the upper part of Table 4. As it turns out, the test detects two cointegration relations on the 5\% level for the four European and US American markets and one cointegration relation for the Japanese NIKKEI 225. This again highlights the problem of distinguishing unit root from near unit root processes since we did not find clear evidence of nonstationarity with the univariate unit root tests presented in Table 2.

For ease of exposition, we report normalized cointegrating equations which are expressed between the levels of stock market indices and the two sentiment indices seperately (see middle part of Table 4), i.e. we report the normalized equations

$$
\begin{aligned}
S_{t}^{I, m}+\bar{\beta}_{1} \log \left(P_{t}^{m}\right)+\hat{\mu}^{I, m} & =\xi_{t}^{I, m} \\
S_{t}^{P, m}+\bar{\beta}_{2} \log \left(P_{t}^{m}\right)+\hat{\mu}^{P, m} & =\xi_{t}^{P, m}
\end{aligned}
$$

where $\bar{\beta}_{1}$ and $\bar{\beta}_{2}$ are the normalized cointegrating coefficients. Clearly, we report only one cointegrating relation for the NIKKEI 225. These cointegration equations show a negative (positive) relation between stock market indices and institutional (individual) sentiment which confirms earlier "experimental" evidence by DeBondt (1993) who finds that institutional investors tend to predict mean reversion whereas individual investors tend to predict trend continuation.

In the lower part of Table 4 we finally show adjustment coefficients $\gamma_{1}, \gamma_{2}$ of the 
error correction mechanism implied by the two cointegration vectors:

$$
\begin{aligned}
\triangle S_{t}^{I, m} & =\mu^{I, m}+\gamma_{1}^{I, m} \xi_{t-1}^{I, m}+\gamma_{2}^{I, m} \xi_{t-1}^{P, m}+\boldsymbol{\Gamma}_{3}^{I, m} \mathbf{y}_{t-1}+\varepsilon_{t}^{I, m} \\
\triangle S_{t}^{P, m} & =\mu^{P, m}+\gamma_{1}^{P, m} \xi_{t-1}^{I, m}+\gamma_{2}^{P, m} \xi_{t-1}^{P, m}+\boldsymbol{\Gamma}_{3}^{P, m} \mathbf{y}_{t-1}+\varepsilon_{t}^{P, m} \\
\triangle \log \left(P_{t}^{m}\right) & =\mu^{m}+\gamma_{1}^{m} \xi_{t-1}^{I, m}+\gamma_{2}^{m} \xi_{t-1}^{P, m}+\boldsymbol{\Gamma}_{3}^{m} \mathbf{y}_{t-1}+\varepsilon_{t}^{m}
\end{aligned}
$$

where $\mathbf{y}_{t-1}$ contains the first lag of the three endogenous variables and t-values for the coefficient estimates are based upon Newey-West (1987) HAC standard errors. For the NIKKEI 225 there is only one adjustment parameter $\gamma$ in the vector error correction model.

For all four European and US American markets the results imply that a rise in stock market $(\log )$ returns leads to a statistically significant lower institutional but higher individual sentiment, i.e. individuals are trend followers, whereas institutionals expect trend reversals. Further inspection of the error correction adjustments reveals that a rising individual sentiment leads to higher stock returns in the following week whereas a rising institutional sentiment is followed by lower returns over the next week for all four European and US American markets. However, the latter effects from sentiment to returns are of statistical significance only for the two European markets DAX and ESX. This makes intuitive sense since we are working with German sentiment 8 Results for the NIKKEI 225 are similar. Institutional sentiment and stock index levels have a negative relation whereas individual sentiment has a positive relation to stock market levels. The dynamic adjustment of institutional and individual sentiment to market returns is also similar to the case for the other four markets.

These results are nicely in line with the predictions of noise trader models and our

\footnotetext{
${ }^{8}$ From the same signs of the adjustment coefficients, it can be expected that sentiment is correlated internationally. However, this correlation does not seem strong enough to yield significant estimates for markets outside Europe.
} 
results in the preceding section. On the one hand, if individual investors really are the proverbial noise traders who get overly optimistic (pessimistic) by past rising (declining) market returns we would expect to find the positive relation between individual sentiment and stock market returns observed in the error correction adjustments here. As suggested by Brown and Cliff (2005) individual sentiment is a proxy for noise trader risk and individual investors drive stock markets above their fundamental values. Institutional investors on the other hand, who were shown to have correct expectations on average in the last section, should forecast mean-reversion which is a well known feature of stock returns over longer horizons (Poterba and Summers, 1988). Furthermore, we find the theoretically expected adjustments in the error correction mechanism. A shift to higher institutional sentiment implies lower returns over short horizons. As discussed above, if institutions aggregate and interpret fundamentals this might well be informative for future discount factors rather than cash flows (Evans and Lyons (2002) find strong evidence for this in FX markets). Then, higher expected returns of institutions point towards an increase in risk (a higher discount factor) which implies lower prices but higher expected returns.

\section{$6 \quad$ Further plausibility checks and some stability considerations}

The results obtained by using bias-adjusted long-horizon regressions and VEC models indicate that individual sentiment is a proxy for noise trader risk and that institutional sentiment is conformable with expectations of smart traders who correctly aggregate fundamentals and form risk-based expectations. Given these results we would expect institutional investors to also take into account noise trader risk by individual investors (hypothesis 3). Furthermore, since institutional sentiment seems to forecast aggregate market returns one might wonder if individual traders 
take advantage of this forecasting relationship and try to infer future institutional sentiment. If individual sentiment really represents noise, they should not exploit this presumably fundamental based information contained in institutional investors' expectations. Both arguments imply that the change in the sentiment of institutions should be affected by their expectations about the sentiment of individuals whereas individuals do not take account institutional sentiment when forming their expectations. We investigate this issue as a further plausibility check of our results obtained so far.

In order to do so, we estimate regressions of the following form:

$$
\begin{aligned}
& \triangle S_{t}^{I, m}=\mu^{I, m}+\alpha^{I, m} S_{t}^{P, m}+\beta^{I, m}(L) \triangle S_{t}^{I, m}+\gamma^{I, m}(L) r_{t}^{m}+\varepsilon_{t}^{I, m} \\
& \triangle S_{t}^{P, m}=\mu^{P, m}+\alpha^{P, m} S_{t}^{I, m}+\beta^{P, m}(L) \triangle S_{t}^{P, m}+\gamma^{P, m}(L) r_{t}^{m}+\varepsilon_{t}^{P, m}
\end{aligned}
$$

where $\beta(L)$ and $\gamma(L)$ are polynomials in the lag operator and we are mainly interested in the parameter estimates of $\alpha^{I, m}$ and $\alpha^{P, m}$ whereas the remaining terms are included as control variables (see for example Wang, Keswany and Taylor (2006) for the importance of controlling for past returns).

Some comments regarding these equations are in order. First, putting the first difference of sentiment on the left hand side and the level of the other group's sentiment on the right hand side serves to estimate whether changes in institutional and individual sentiment can be explained by the level of the other group's sentiment as discussed above. Second, since the level of the other investor group's sentiment is unknown, and, more seriously, the regressions as stated above will suffer from simultaneity, we have to instrument for the level of sentiment in both equations. This IV approach also makes sense from an economic viewpoint, since we are essentially asking the following question for each of the two investor groups: how does my expectation of the other's group sentiment influence the change in my own sentiment? We do so by using as instruments all predetermined variables on the right hand side 
of the respective equations, i.e. lags of market returns and own changes in sentiment, and by further adding lagged levels of the sentiment we want to instrument for. As an example, consider the first of the above two equations concerning the change in institutional sentiment. Here we use lagged changes in institutional sentiment, lagged log returns and lagged values of individual sentiment $S_{t-1}^{P, m}, S_{t-2}^{P, m}, \ldots$ In order to free residuals from autocorrelation we use two lags of all variables. Estimation is carried out via GMM where t-values are based on Newey-West HAC standard errors.

The results are presented in Table $\mathbf{5}$ and show that institutional investors (left part of the table) consistently adjust their sentiment downwards (upwards) when they expect individual sentiment to be high (low) which is consistent with the noise trader risk story of Brown and Cliff (2005) and our third hypothesis. Furthermore, as can be seen from the right part of Table 5, individual investors do not take into account expected institutional sentiment, thereby neglecting relevant information.

A possible explanation for this finding might be, that individual investors need time to learn about the forecasting power of institutional sentiment for future stock returns as this relation was not obvious right from the beginning of this investor survey. Therefore, one might expect individual investors to rely more heavily on institutional sentiment towards the end of the sample when they had the chance to learn about the information contained in institutional sentiment. Indeed, taking a second look at Figure 1, it seems that both sentiment indices track each other more closely towards the end of the sample which might indicate a structural break. However, redoing the above analysi:9 presented in Table 5 for only the last year of our sample does not lead to qualitatively different results. Furthermore, this positive comovement is not uncommon for the sentiment indices. As an example Figure 3 shows the time-varying correlation of the two DAX sentiment indices based upon a

\footnotetext{
${ }^{9}$ We do not report the results here to conserve space.
} 
simple rolling window estimation of 3 months (dark line) and one year (grey line). As can be seen for both the short and longer frequency, the correlation is positive during several subsamples and not just towards the end of the sample period. Results for the other European and US American markets are very similar. Correlations for the NIKKEI are typically positive.

Stability analyses for the long-horizon regressions and VEC models are difficult since we need a long sample to reliably estimate these models and not just the last 50 observations or so. If we do estimate these models on the last 50 weeks anyway, we find somewhat weaker results than over the full sample. Although institutional sentiment still forecasts future excess returns, individual sentiment is no longer associated with statistically significant negative future returns and we find only one cointegration relationship in the VECM analyses. However, it is unclear whether these results really come from a structural break towards the end of the sample or just from selecting a short and unusual subsample which provides less precise estimation results. Therefore, it will be interesting to see, whether these results hold in a genuine out of sample test or if individual investors eventually learn about the information contained in institutional sentiment.

\section{Conclusion}

Evidence on the role of individuals and institutions in financial markets is mixed. While several papers find evidence that individual sentiment proxies for noise trader risk (Brown and Cliff, 2005, Kumar and Lee, 2004, Bange, 2000) there is rare evidence on genuine institutional sentiment. We jointly investigate sentiment from both institutions and individuals and find that (i) individuals seem to proxy for noise trader risk in a new data set and that (ii) institutional sentiment seems to proxy for smart money which confirms our first two hypotheses. 
These results show up in both long-horizon regressions where we adjust for the disturbing effects of persistent regressors and also in VECM analyses. The former show that institutions (individuals) consistently have correct (incorrect) expectations for all five markets over medium horizons. VECM models reveal that institutions forecast mean reversion of stock returns, whereas individuals forecast trend continuation and that, at least for the European markets, sentiment partly drives stock returns in a way consistent with the noise trader and smart money hypothesis.

As a final check for plausibility of the noise trader interpretation of our results, we investigate cross effects of one group's sentiment on the change of the other group's sentiment. Consistent with the previuos findings, higher (lower) expected individual sentiment decreases (increases) institutional sentiment whereas individuals do not take into account the information contained in institutional sentiment which confirms our third hypothesis.

Overall the results also provide evidence that survey data may be useful for forecasting financial and economic variables which supports the findings of Ang, Bekaert and Wei (2006).

As we argue towards the end of the last section, it will be interesting to see whether the relationships between sentiment and stock returns hold out of sample or whether individuals eventually learn about the information contained in institutional sentiment. 


\section{Literature}

Amihud, Yakov and Clifford M. Hurvich (2004). Predictive regressions: a reducedbias estimation method. Journal of Financial and Quantitative Analysis, 39, p. 813841.

Ang, Andrew, Geert Bekaert and Min Wei (2006). Do macro variables, asset markets or surveys forecast inflation better?. New version of NBER Working Paper 11538.

Antweiler, Werner and Murray Z. Frank (2003). Is all that talk just noise? The information content of internet stock message boards. Journal of Finance 59, p. 1259-1294.

Bacchetta, Phillippe and Eric van Wincoop (2004). A scapegoat model of exchangerate fluctuations. American Economic Review, Papers and Proceedings, 94, p. 114118.

Badrinath, S.G. and Sunil Wahal (2002). Momentum trading by institutions. Journal of Finance, 62, 2449-2478.

Baker, Malcolm P. and Jeffrey Wurgler (2006). Investor sentiment and the crosssection of stock returns. Journal of Finance, forthcoming.

Bange, Mary M. (2000). Do the portfolios of small investors reflect positive feedback trading?. Journal of Financial and Quantitative Analysis, 35, p. 239-255.

Barberis, Nicholas, Andrei Shleifer and Robert Vishny (1998). A model of investor sentiment. Journal of Financial Economics, 49, p. 307-343.

Bodurtha, Jr., James N., Dong-Soon Kim and Charles M.C. Lee (1995). Closed-end country funds and U.S. market sentiment. Review of Financial Studies, 8, p. 879-918. 
Boyd, John H., Jian Hu and Ravi Jagannathan (2005). The stock market's reaction to unemployment news: Why bad news is usually good for stocks. Journal of Finance, 60, p. 649-672.

Brown, Gregory and Michael T. Cliff (2004). Investor sentiment and the near-term stock market (2004). Journal of Empirical Finance, 11, p. 1-27.

Brown, Gregory and Michael T. Cliff (2005). Investor sentiment and asset valuation. Journal of Business, 78, 405-440.

Campbell, John Y. and Albert S. Kyle (1993). Smart money, noise trading and stock price behaviour. Review of Economic Studies, 60, p. 1-34.

Campbell, John Y., Tarun Ramadorai and Tuomo Vuolteenaho (2005). Caught on tape: Institutional order flow and stock returns. NBER Working Paper 11439.

Chakravarty, Sugato (2001), Stealth-trading: Which trader's trades move stock prices?. Journal of Financial Economics, 61, 289-307.

Chen, Honghui, Gregory Noronha and Vijay Singal (2004). The price response to S\&P 500 index additions and deletions: Evidence of asymmetry and a new explanation. Journal of Finance, 59, p. 1901-1930.

Cochrane, John H. (1991). A critique of the application of unit root tests. Journal of Economic Dynamics and Control, 15, 275-284.

Conrad, Jennifer, Bradford Cornell and Wayne R. Landsmann (2002), When is bad news really bad news?. Journal of Finance, 57:6, 2507-2532.

DeBondt, Werner F. M. (1993). Betting on trends: Intutitive forecasts of financial risk and return. International Journal of Forecasting, 9, 355-371. 
DeLong, J. Bradford, Andrei Shleifer, Lawrence H. Summers and Robert J. Waldmann (1990). Noise trader risk in financial markets. Journal of Political Economy, 98:4, 703-738.

Dickey, David A. and Wayne A. Fuller (1979). Distribution of the estimators for autoregressive time series with a unit root. Journal of the American Statistical Association, 74 , p. 427-431.

Elliott, Graham, Thomas J. Rothenberg and James H. Stock (1996). Efficient tests for an autoregressive unit root. Econometrica, 64, p. 813-836.

Engle, Robert F. and C. W. J. Granger (1987). Cointegration and error correction: Representation, estimation, and testing. Econometrica, 55, p. 251-276.

Evans, Martin D. and Richard K. Lyons (2002). Order flow and exchange rate dynamics. Journal of Political Economy, 110, 170-180.

Fama, Eugene (1998). Market efficiency, long-term returns, and behavioral finance. Journal of Financial Economics, 49, 283-306.

Ferson, Wayne E., Sergei Sarkissian and Timothy T. Simin (2003). Spurious regressions in financial economics?. Journal of Finance, 63, p. 1393-1412.

Frazzini, Andrea and Owen A. Lamont (2005). Dumb money: Mutual fund flows and the cross-section of stock returns. NBER Working paper 11526.

Gervais, Simon and Ron Kaniel (2001). The high-volume return premium. Journal of Finance, 56, p. 877-919.

Griffin, John M., Jeffrey H. Harris and Selim Topaloglu (2003). The dynamics of institutional and individual trading. Journal of Finance, 58, p. 2285-2320.

Griffin, John M., Jeffrey H. Harris and Selim Topaloglu (2005). Who drove and burst the tech bubble?, Working Paper, University of Texas. 
Hamilton, James D. (2994). Time series analysis. Princeton: Princeton University Press.

Johansen, Søren (1991). Estimation and hypothesis testing of cointegration vectors in gaussian vector autoregressive models. Econometrica, 59, p. 1551-1580.

Jones, Charles M. and Marc. Lipson (2004). Are retail orders different?. Working paper, Columbia University.

Kaniel, Ron, Gideon Saar and Sheridan Titman (2005). Individual investor sentiment and stock returns. Working Paper, Duke University.

Kumar, Alok and Charles M. Lee (2004) Retail investor sentiment and return comovement. Journal of Finance, forthcoming.

Kyle, Albert S. (1985). Continuous auctions and insider trading. Econometrica, 53, $1315-1336$.

Lee, Wayne Y., Christine X. Jiang and Daniel C. Indro (2002). Stock market volatility, excess returns, and the role of investor sentiment. Journal of Banking and Finance, 26, p. 2277-2299.

Ljung, G. and George E. P. Box (1987). On a measure of lack of fit in time series models. Biometrika, 66, p. 67-72.

Neal, Robert and Simon M. Wheatley (1998). Do measures of investor sentiment predict returns?. Journal of Financial and Quantitative Analysis, 33, p. 523-547.

Newey, Whitney and Kenneth West (1987). A simple positive semi-definite, heteroskedasticity and autocorrelation consistent covariance matrix. Econometrica, 55, p. $703-708$.

Nofsinger, John R. and Richard W. Sias (1999). Herding and feedback trading by institutional and individual investors. Journal of Finance, 59, p. 2263-2295. 
Perron, Pierre and Peter C.B. Phillips (1988). Testing for a unit root in time series regression. Biometrika, 75, p. 335-346.

Polk, Christopher and Paolo Sapienza (2004). The real effects of investor sentiment. NBER Working paper 10563.

Poterba, James M. and Lawrence H. Summers (1988). Mean reversion in stock prices: Evidence and implications. Journal of Financial Economics, 22, p. 27-59.

Shiller, Robert J. (2003). From efficient markets theory to behavioral finance. Journal of Economic Perspectives, 17, 83-104.

Sias, Richard W. (2004). Institutional herding. Review of Financial Studies, 17, p. $165-206$

Sias, Richard, Laura T. Starks and Sheridan Titman (2004). Changes in institutional ownership and stock returns: Assessment and methodology. Journal of Business, forthcoming.

Stambaugh, Robert F. (1999). Predictive regressions. Journal of Financial Economics, 54, p. 375-421.

Temin, Peter and Hans-Joachim Voth (2004). Riding the south sea bubble, American Economic Review, 94, 1654-1668.

Valkanov, Rossen (2003). Long-horizon regressions: Theoretical results and applications. Journal of Financial Economics, 68, p. 201-232.

Wang, Yaw-huei, Aneel Keswani and Stephen J. Taylor (2006). The relationships between sentiment, returns and volatility. International Journal of Forecasting, 22, 109-123.

Zheng, Lu (1999). Is money smart? A study of mutual fund investors' fund selection ability. Journal of Finance, 54, 901-933. 


\section{A Appendix}

The simulation procedure we employ is based on simulating new time series for each regressor to obtain bias adjusted confidence intervals for point estimates. Therefore we regress average excess returns on the two sentiment variables and control variables

$$
\frac{1}{k} \sum_{\kappa=1}^{k} r_{t+\kappa}^{e}=\beta_{0}^{(k)}+\beta_{1}^{(k)} S_{t}^{I}+\beta_{2}^{(k)} S_{t}^{P}+\Theta_{t} \gamma^{(k)}+\varepsilon_{t}^{(k)}
$$

where $r_{t+1}^{e}$ is the market excess return over the risk-free rate from week $t$ to $t+1$. For all five markets we investigate, the control variables in $\Theta$ include log changes in the respective countries' CPI and monetary aggregate M3 (the monetary base for Japan). We further include changes in dividend yields ${ }^{10}$, short term (1 month) interest rates and the term spread (difference of yields for maturities of 10 years and 3 months) and the lagged market return. For the two US markets we further include the quality spread (difference of yields for bonds rated Baa and AAA) and the HML and SMB factors.

The simulation for each of the five stock market indices works as follows. We estimate a VAR(1)-Model that includes all variables in the above equation and imposes the null hypothesis that $\beta_{1}$ and $\beta_{2}$ are zero by setting the corresponding coefficients in the VAR to zero. The residuals are stored. Next, we bootstrap the residuals and recursively generate 10,000 new time series of the original length for all variables. With these simulated time series in hand we estimate equation (2) for horizons of $1,2, \ldots, 60$ weeks and save the estimated coefficients $\widetilde{\beta}_{1}^{(k)}, \widetilde{\beta}_{2}^{(k)}$ for each horizon $k$ over the 10,000 simulations. Note that the same 10,000 simulated time series can be used for every horizon. Standard errors of all regression coefficients in the simulation are corrected for autocorrelation up to the $k-1$ th lag. This provides us with the empirical distribution of the point estimates which can in turn be used to perform bias-adjustments.

\footnotetext{
${ }^{10}$ Taken from Bloomberg, on a daily frequency.
} 


\section{Table 1. Descriptive Statistics}

This table shows descriptive statistics for several variables employed in the empirical analysis separately for each stock market index. DAX denotes the DAX30, ESX the EuroStoxx50, ND stands for the NASDAQ100, SP for the S\&P500 and NK for the NIKKEI225. Panel A shows statistics for log returns. $Q(10)$ denotes the Ljung-Box test statistic for autocorrelation up to the tenth order. $Q^{2}(10)$ shows the test statistic for the null of no autocorrelation in squared residuals up to the tenth order. The residuals employed are filtered from an MA(1) model. JB gives the value of the Jarque-Bera test statistic computed with the filtered residuals described above to eliminate the effect of autocorrelation. Panel $\mathrm{B}$ and Panel $\mathrm{C}$ give the same statistics for institutional and private investors' sentiment $P$-values are in parentheses.

\begin{tabular}{lrrrrr}
\multicolumn{7}{c}{ PANEL A: Return statistics } \\
\hline \hline DAX & ESX & ND & SP & NK \\
\hline mean & -0.002 & -0.002 & -0.001 & 0.000 & -0.001 \\
median & 0.003 & 0.001 & -0.001 & 0.001 & 0.001 \\
max & 0.129 & 0.136 & 0.206 & 0.075 & 0.095 \\
min & -0.139 & -0.179 & -0.192 & -0.123 & -0.077 \\
std. dev. & 0.038 & 0.035 & 0.046 & 0.025 & 0.030 \\
skew & -0.134 & -0.532 & -0.002 & -0.622 & 0.009 \\
kurt & 4.144 & 6.676 & 5.565 & 6.482 & 2.668 \\
\hline$Q(10)$ & 16.217 & 9.435 & 9.043 & 11.346 & 3.568 \\
& $(0.094)$ & $(0.491)$ & $(0.528)$ & $(0.331)$ & $(0.965)$ \\
$Q^{2}(10)$ & 45.882 & 28.086 & 30.551 & 10.971 & 5.217 \\
& $(0.000)$ & $(0.001)$ & $(0.000)$ & $(0.278)$ & $(0.815)$ \\
JB & 11.397 & 120.824 & 54.289 & 112.822 & 0.912 \\
& $(0.003)$ & $(0.000)$ & $(0.000)$ & $(0.000)$ & $(0.634)$ \\
\hline \hline
\end{tabular}


Table 1. (continued)

PANEL B: Institutional sentiment statistics

\begin{tabular}{lrrrrr}
\hline \hline & DAX & ESX & ND & SP & NK \\
\hline mean & 0.1398 & 0.1508 & 0.0507 & 0.0500 & 0.1795 \\
median & 0.1600 & 0.1765 & 0.0526 & 0.0571 & 0.2143 \\
max. & 0.4762 & 0.4524 & 0.3889 & 0.4000 & 0.6250 \\
min. & -0.1563 & -0.2045 & -0.2857 & -0.2800 & -0.5172 \\
std. dev. & 0.1323 & 0.1384 & 0.1219 & 0.1190 & 0.1918 \\
skew & -0.2635 & -0.3871 & 0.1344 & -0.0249 & -0.7223 \\
kurt & 2.4887 & 2.5167 & 2.6805 & 3.1171 & 3.4334 \\
\hline$Q(10)$ & 0.3456 & 0.3296 & 0.2545 & 0.2466 & 0.5974 \\
& $(0.0000)$ & $(0.0000)$ & $(0.0000)$ & $(0.0000)$ & $(0.0000)$ \\
$Q^{2}(10)$ & 0.2541 & 0.1950 & 0.0037 & 0.0576 & 0.0812 \\
& $(0.0000)$ & $(0.0000)$ & $(0.0000)$ & $(0.0000)$ & $(0.0000)$ \\
JB & 1.1238 & 2.6836 & 1.1651 & 3.4187 & 43.9623 \\
& $(0.5701)$ & $(0.2614)$ & $(0.5584)$ & $(0.1812)$ & $(0.0000)$ \\
\hline \hline
\end{tabular}

PANEL C: Individual sentiment statistics

\begin{tabular}{lrrrrr}
\hline \hline & DAX & ESX & ND & SP & NK \\
\hline mean & 0.0925 & 0.1041 & 0.0470 & 0.0378 & 0.1073 \\
median & 0.0791 & 0.0956 & 0.0400 & 0.0296 & 0.1429 \\
max. & 0.4000 & 0.4222 & 0.4259 & 0.3864 & 0.4222 \\
min. & -0.1881 & -0.1837 & -0.2222 & -0.2293 & -0.2768 \\
std. dev. & 0.1108 & 0.1035 & 0.1217 & 0.1172 & 0.1867 \\
skew & 0.3922 & 0.2635 & 0.5055 & 0.2461 & -0.1644 \\
kurt & 3.0705 & 2.9764 & 3.1504 & 3.0040 & 1.7745 \\
\hline$Q(10)$ & 0.2997 & 0.2979 & 0.4072 & 0.3848 & 0.6240 \\
& $(0.0000)$ & $(0.0000)$ & $(0.0000)$ & $(0.0000)$ & $(0.0000)$ \\
$Q^{2}(10)$ & 0.1726 & 0.0293 & 0.1831 & 0.1496 & 0.1000 \\
& $(0.0000)$ & $(0.0176)$ & $(0.0000)$ & $(0.0000)$ & $(0.0000)$ \\
JB & 3.3586 & 0.4904 & 9.6775 & 4.5938 & 4.0731 \\
& $(0.1865)$ & $(0.7852)$ & $(0.0008)$ & $(0.1008)$ & $(0.1306)$ \\
\hline \hline
\end{tabular}


Table 2. Unit root tests for sentiment indices

This table shows unit root tests for the ten sentiment indices over the whole sample. PP denotes the Phillips-Perron test, ADF the Augmented Dickey Fuller test and DF-GLS is the Dickey Fuller test with GLS detrending. Numbers in parentheses are p-values for the first two tests.

\begin{tabular}{lrrr}
\hline \hline & PP & ADF & DF-GLS \\
\hline$S^{I, D A X}$ & -8.083 & -4.484 & -3.079 \\
& $(0.000)$ & $(0.000)$ & $(<0.010)$ \\
$S^{P, D A X}$ & -6.726 & -4.253 & -1.752 \\
& $(0.000)$ & $(0.001)$ & $(>0.050)$ \\
$S^{I, E S X}$ & -7.996 & -4.572 & -2.211 \\
& $(0.000)$ & $(0.000)$ & $(<0.050)$ \\
$S^{P, E S X}$ & -6.427 & -4.388 & -2.703 \\
& $(0.000)$ & $(0.000)$ & $(<0.010)$ \\
$S^{I, N D}$ & -9.640 & -5.534 & -1.312 \\
& $(0.000)$ & $(0.000)$ & $(>0.100)$ \\
$S^{P, N D}$ & -5.610 & -4.068 & -3.571 \\
& $(0.000)$ & $(0.001)$ & $(<0.010)$ \\
$S^{I, S P}$ & -9.214 & -5.585 & -0.902 \\
& $(0.000)$ & $(0.000)$ & $(>0.100)$ \\
$S^{P, S P}$ & -5.766 & -4.270 & -3.913 \\
& $(0.000)$ & $(0.001)$ & $(<0.010)$ \\
$S^{I, N K}$ & -4.510 & -3.561 & -0.846 \\
& $(0.000)$ & $(0.007)$ & $(>0.100)$ \\
$S^{P, N K}$ & -3.469 & -2.804 & -2.641 \\
& $(0.010)$ & $(0.060)$ & $(<0.010)$ \\
\hline \hline
\end{tabular}


Figure 1. Sentiment and stock market indices

This figure shows the time series of stock market indices (thick dark line and right axis) and the time series of both individual (thin dark line and left axis) and institutional sentiment (thin grey line and left axis).
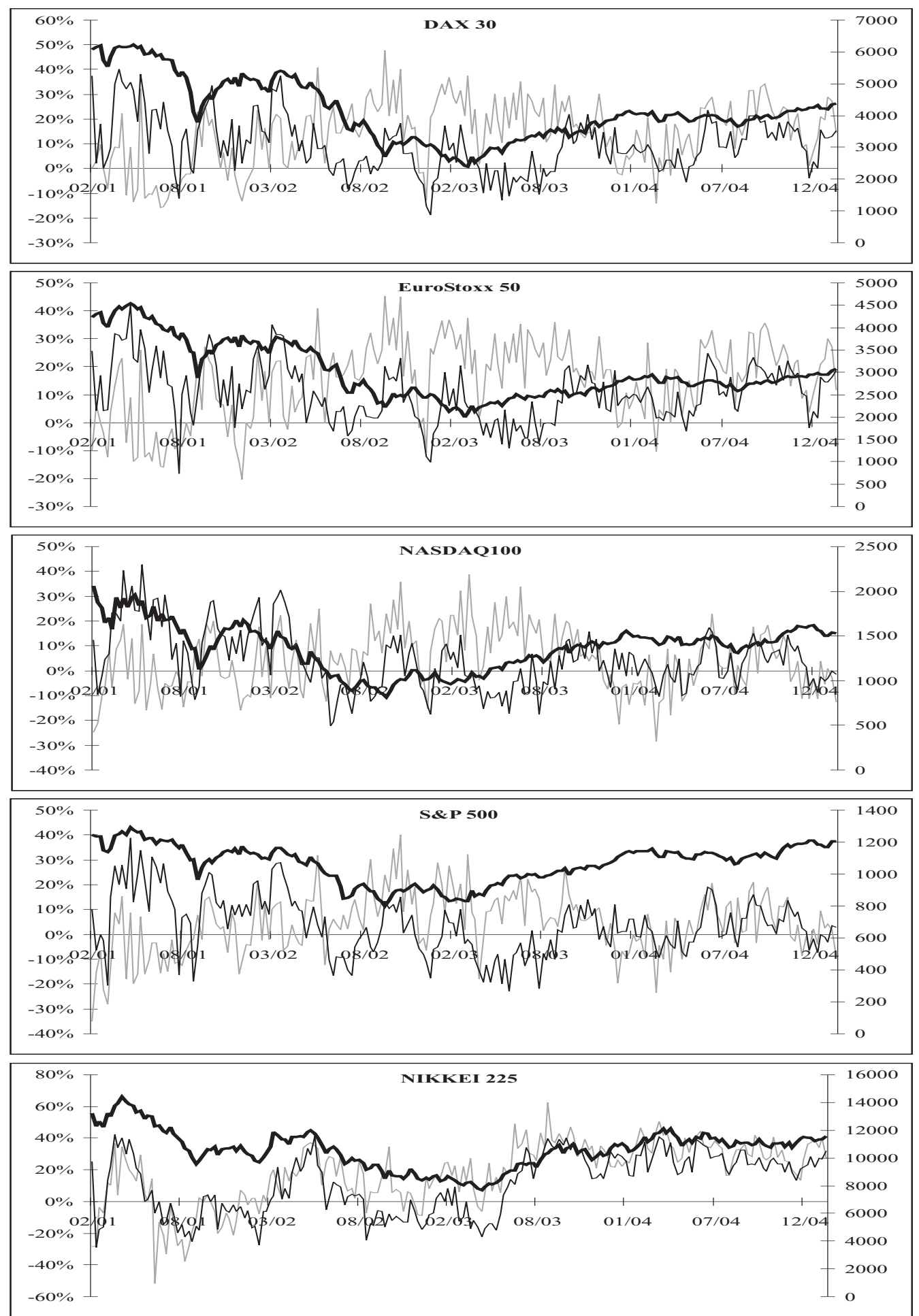
Table 3. Results from long-horizon regressions

This table shows results from long-horizon regressions of the form

$$
\frac{1}{k} \sum_{\kappa=1}^{k} r_{t+\kappa}^{e, m}=\beta_{0}^{(k), m}+\beta_{1}^{(k), m} S_{t}^{I, m}+\beta_{2}^{(k), m} S_{t}^{P, m}+\Theta_{t}^{m} \gamma^{(k), m}+\varepsilon_{t}^{(k), m}
$$

where $r^{e, m}$ is the (log) excess return for market $m(m=\mathrm{DAX}, \mathrm{ESX}, \ldots), S^{I, m}\left(S_{t}^{P, m}\right)$ is the sentiment index of institutional (individual) investors for market $m$, and $\Theta_{t}^{m}$ is time $t$ vector of market specific control variables detailed in Appendix 1. $k$ represents the horizon in weeks. The second column of the table shows bias-adjusted coefficient estimates of $\beta_{1}^{(k), m}$ and $\beta_{2}^{(k), m}$ for the horizon of $k=24$ weeks along with p-values in parentheses which are based on the simulated small sample distribution of the test statistics. The fourth column shows the bias in the coefficient estimate $\psi$ (in percent) whereas the fifth column shows simulated 5\% critical values ( $t^{l}$ and $t^{u}$ for the lower and upper critical value) for the null that the respective coefficient is zero. RMSE represents the root mean square error of the forecast, Bias \%, Var. \% and Covar. \% show the decomposition of the RMSE and TU is Theil's U.

\begin{tabular}{|c|c|c|c|c|c|c|c|}
\hline & coef. & $\overline{\operatorname{adj} . R^{2}}$ & $\psi$ & $\bar{t}^{l} / t^{u}$ & & & $\overline{\mathrm{TU}}$ \\
\hline$S^{I, D A X}$ & 0.016 & \multirow{4}{*}{0.169} & \multirow{2}{*}{2.102} & -3.209 & RMSE & 0.008 & \multirow{4}{*}{0.567} \\
\hline \multirow{3}{*}{$S^{P, D A X}$} & $(0.061)$ & & & 3.689 & Bias \% & 0.000 & \\
\hline & -0.024 & & \multirow{2}{*}{3.966} & -3.221 & Var. \% & 0.356 & \\
\hline & $(0.049)$ & & & 3.522 & Covar. $\%$ & 0.644 & \\
\hline \multirow[t]{2}{*}{$S^{I, E S X}$} & 0.014 & \multirow{4}{*}{0.276} & \multirow{2}{*}{2.533} & -3.384 & RMSE & 0.007 & \multirow{4}{*}{0.556} \\
\hline & $(0.058)$ & & & 3.586 & Bias \% & 0.000 & \\
\hline \multirow[t]{2}{*}{$S^{P, E S X}$} & -0.024 & & \multirow{2}{*}{5.307} & -3.515 & Var. $\%$ & 0.379 & \\
\hline & $(0.053)$ & & & 3.774 & Covar. $\%$ & 0.621 & \\
\hline \multirow[t]{2}{*}{$S^{I, N D}$} & 0.032 & \multirow{4}{*}{0.490} & \multirow{2}{*}{-2.243} & -3.484 & RMSE & 0.007 & \multirow{4}{*}{0.451} \\
\hline & $(0.007)$ & & & 4.425 & Bias \% & 0.000 & \\
\hline \multirow[t]{2}{*}{$S^{P, N D}$} & -0.037 & & \multirow{2}{*}{3.539} & -4.344 & Var. \% & 0.207 & \\
\hline & $(0.002)$ & & & 3.349 & Covar. $\%$ & 0.794 & \\
\hline \multirow[t]{2}{*}{$S^{I, S P}$} & 0.019 & \multirow{4}{*}{0.483} & \multirow{2}{*}{-0.556} & -3.609 & RMSE & 0.004 & \multirow{4}{*}{0.505} \\
\hline & $(0.001)$ & & & 3.464 & Bias \% & 0.000 & \\
\hline \multirow[t]{2}{*}{$S^{P, S P}$} & -0.021 & & \multirow{2}{*}{4.629} & -3.292 & Var. \% & 0.256 & \\
\hline & $(0.003)$ & & & 3.288 & Covar. $\%$ & 0.744 & \\
\hline \multirow[t]{2}{*}{$S^{I, N K}$} & 0.014 & \multirow{4}{*}{0.127} & \multirow{2}{*}{-4.083} & -3.135 & RMSE & 0.006 & \multirow{4}{*}{0.699} \\
\hline & $(0.043)$ & & & 3.676 & Bias \% & 0.000 & \\
\hline \multirow[t]{2}{*}{$S^{P, N K}$} & -0.014 & & \multirow{2}{*}{14.249} & -4.469 & Var. \% & 0.512 & \\
\hline & $(0.060)$ & & & 3.394 & Covar. \% & 0.488 & \\
\hline
\end{tabular}


Figure 2. Long-horizon regressions at different horizons

This figure presents results from long-horizon regressions of excess returns on institutional and private sentiment as well as several other control factors. Displayed are the average weekly returns for one standard deviation movements in both sentiment variables for horizons up to 60 weeks. The left (right) side always shows institutional (individual) sentiment. The vertical axis measures average excess returns per week and the horizontal axis displays the horizon.
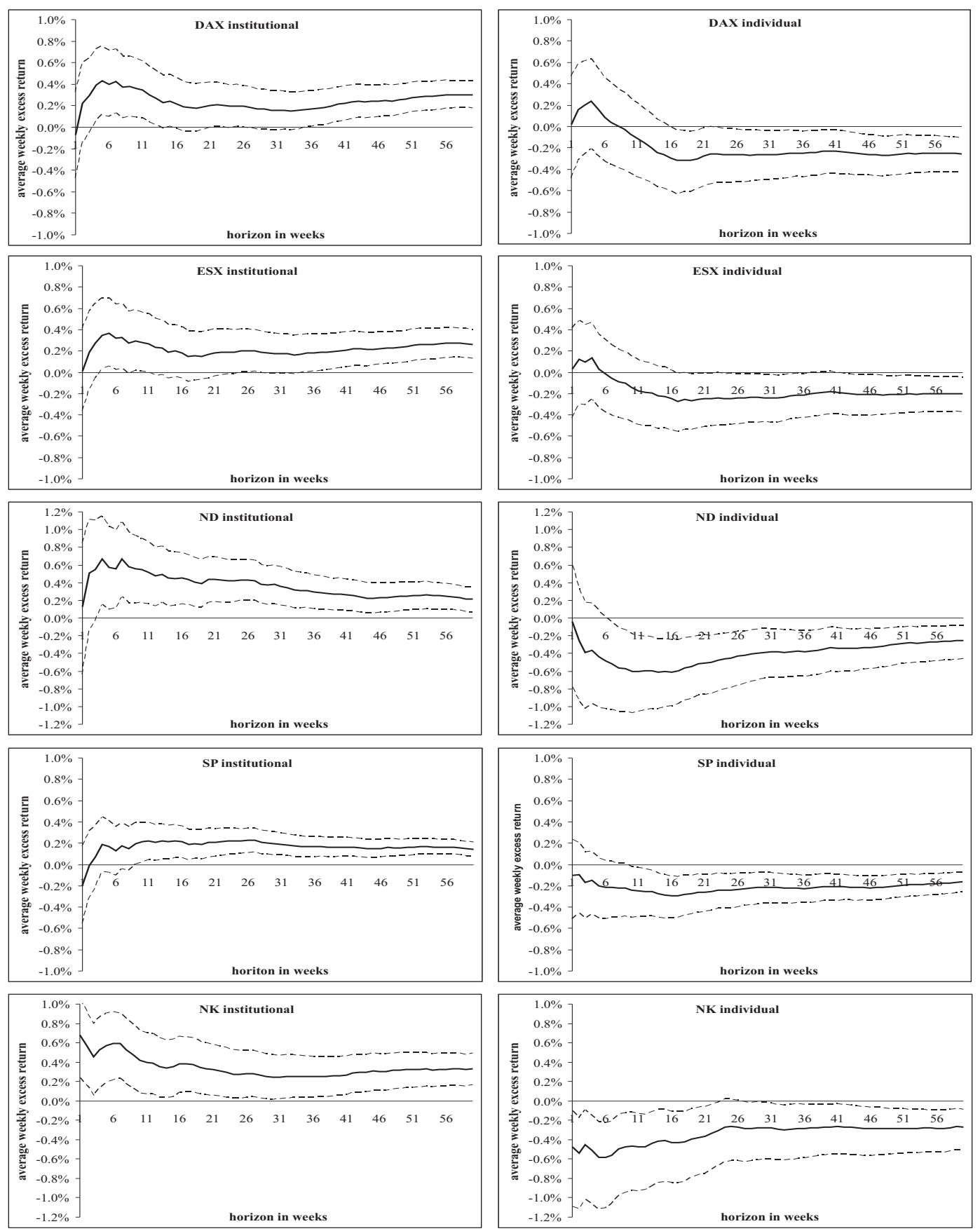


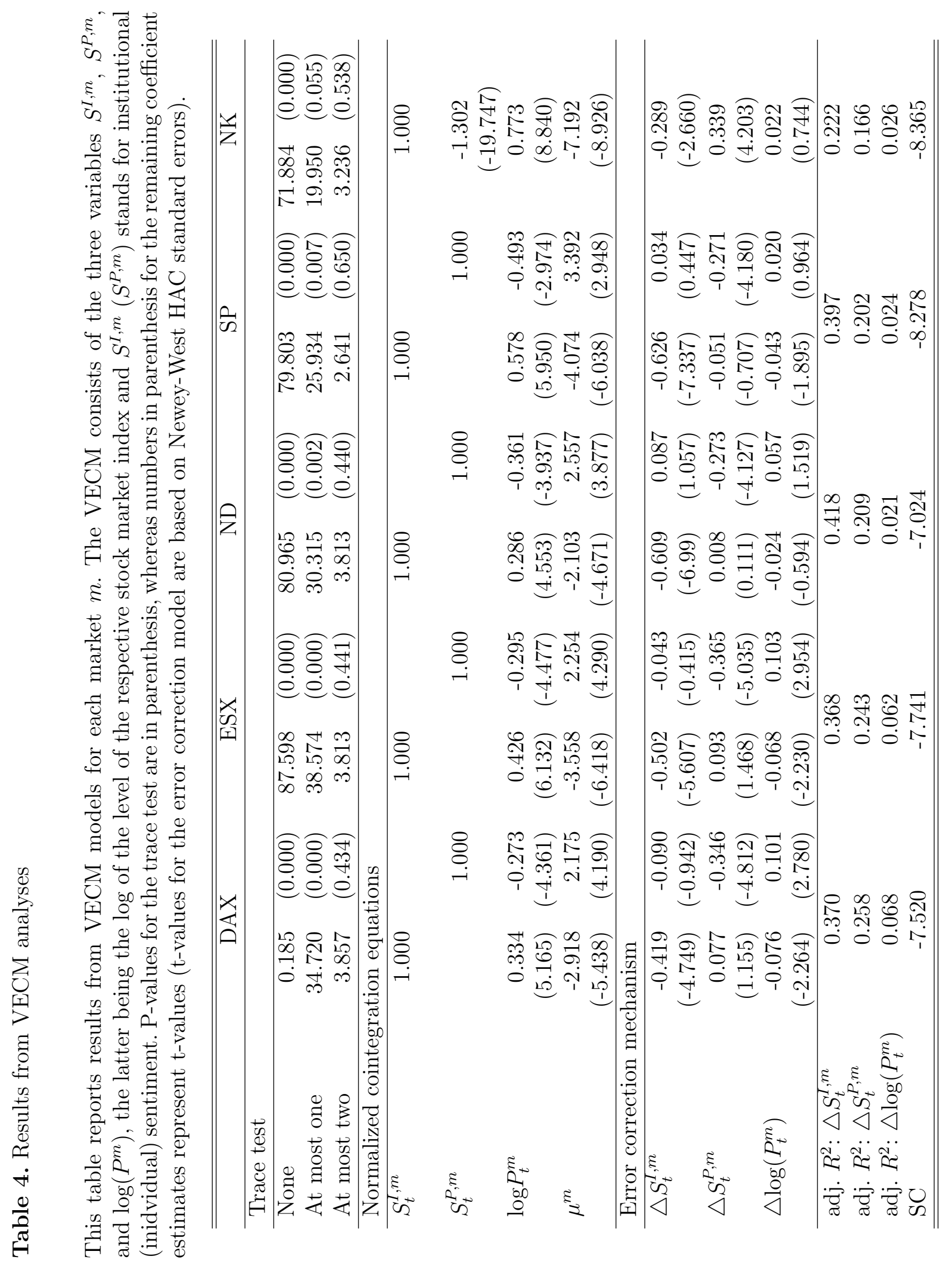




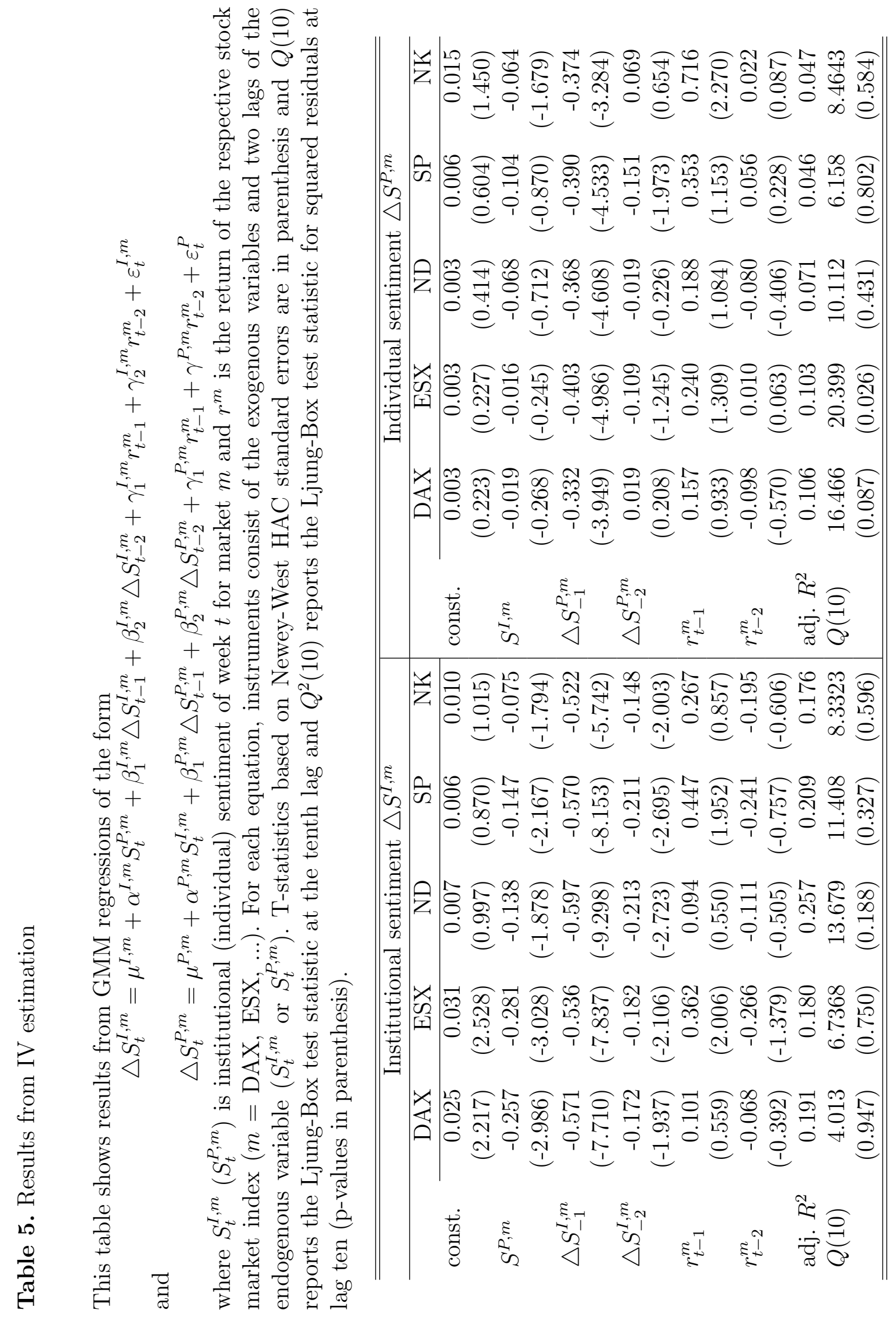


Figure 3. Rolling correlation for the DAX sentiment indices

This figure presents simple rolling window correlations of individual and institutional DAX sentiment. The dark (grey) line shows the correlation for a three months (one year) rolling window.

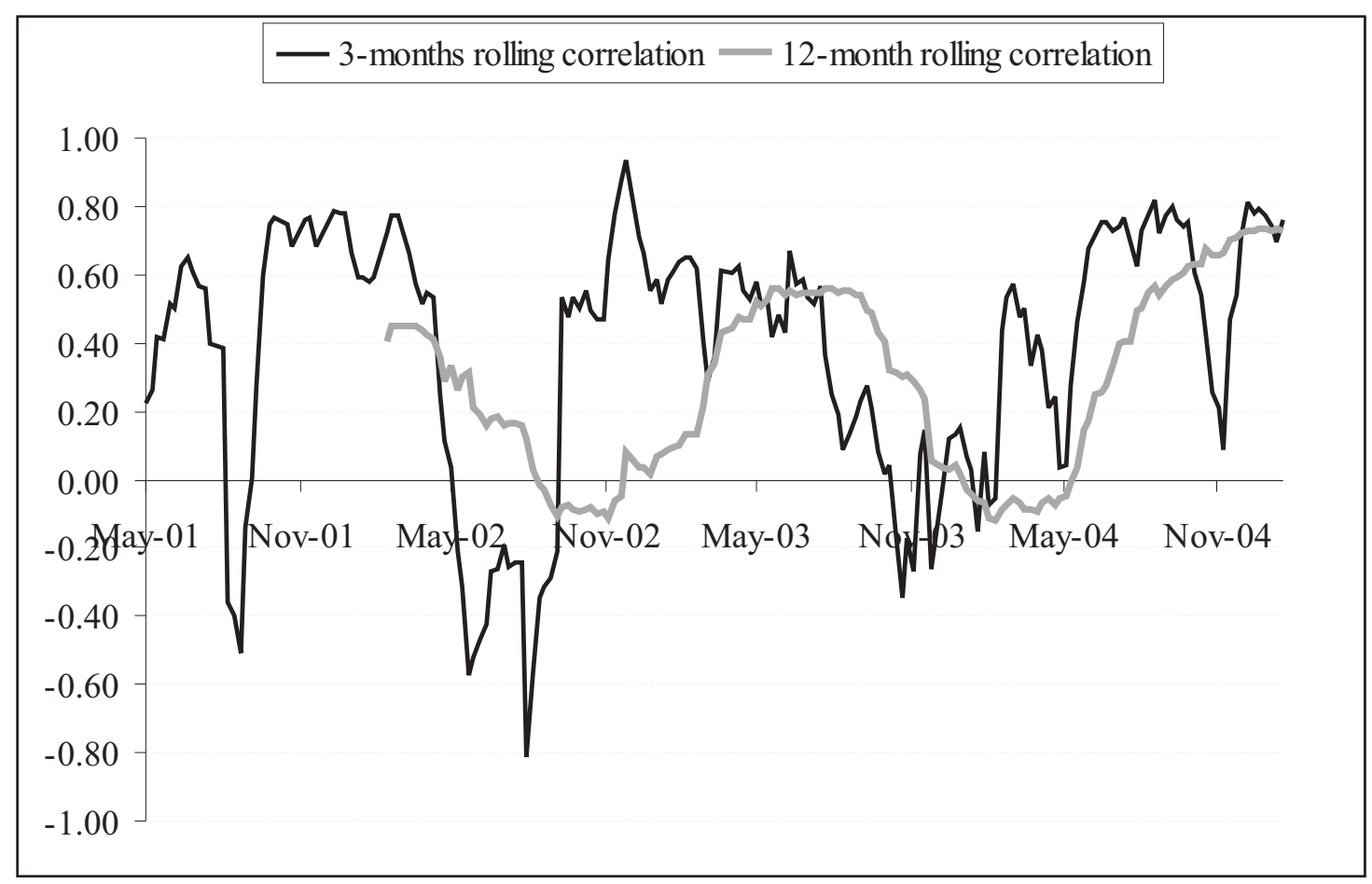

